\title{
Effects of Carbon Nanotubes on a Neuronal Cell Model In Vitro
}

\author{
John Bang', Susan Yeyeodu', Naila Gilyazova', Sam Witherspoon², and Gordon Ibeanu ${ }^{2,3^{*}}$
}

' Department of Environmental, Earth and Geospatial Sciences, North Carolina Central University, 2105 Mary M. Townes Science Building, 1801 Fayetteville St., Durham, NC 27707, USA; ${ }^{2}$ Biomanufacturing Research Institute and Technology Enterprise, North Carolina Central University, 302 East Lawson St., Durham, NC 27707, USA; ${ }^{3}$ Department of Pharmaceutical Sciences, North Carolina Central University, 302 East Lawson St., Durham, NC 27707, USA

Received: July 11, 2011 / Accepted: August 19, 2011

\begin{abstract}
As the use of nanomaterials continues to flourish in industrial and biomedical applications so does the concern that these materials may have unanticipated and undesirable effects on human health and the environment. Inhaled or ingested nanoparticles have been detected in the brain, among other organs, raising the question as to their effect on neuronal viability. The effects of multi-walled carbon nanotubes ( $M W$ CNTs) on the viability of NeuroScreen-1 (NS-1) cells, a neuronal cell model, were studied. Resazurin reduction and in situ Hoechst and propidium iodide (PI) double staining indicated MWCNTs reduce cell viability. Caspase 3/7 activity on par with etoposide-induced apoptosis was not observed until 72 hours and was only $\mathbf{2 0}-\mathbf{3 0} \%$ higher than controls. However, increased levels of annexin $\mathbf{V}$ in the outer leaflet of the cell plasma membranes after 24 hours and a minimum two-fold increase in relative mitochondrial depolarization after 48 hours both suggested MWCNTs promoted apoptosis in this neuronal cell model.
\end{abstract}

Keywords: NeuroScreen-1, Carbon nanotubes, Hypodiploid, Neuronal viability, Pheochromocytoma, Pathway Finder.

* Corresponding author: gibeanu@nccu.edu

\section{Introduction}

Recent developments in medicine and industry involve increasingly the production and use of nanomaterials. While the intended uses of these materials are to benefit human health and the environment, it is not yet clear whether their existence and use has harmful consequences.

Carbon nanotubes (CNTs) have come to the forefront in the past decades as one of the most promising nanomaterials. Although other species have been reported, there are basically two types of CNTs which differ in the number of helical layers they contain. These are designated as single-walled carbon nanotubes (SWCNTs) and multi-walled carbon nanotubes (MWCNTs). CNTs possess certain properties which are highly desirable in several fields and applications, including their small size, electrical conductivity, strength and flexibility (Baughman et al., 2002; Malarkey and Parpura, 2007; Saito et al., 2009). However, CNTs have recently been rated environmentally toxic (Kahru and Dubourguier, 2010).

Early in vivo studies with non-carbon based nanoparticles demonstrated that either ingestion or inhalation of these particles could result in their accumulation in the brain (El-Ansary and Al-Daihan, 2009). While inhaled CNTs are toxic to pulmonary, 
circulatory and immune systems (Madl and Pinkerton, 2009) their effect on the central nervous system is not known. Therefore, further studies in vivo are needed to determine the effects of CNT exposure in the central and peripheral nervous systems. In vitro studies have provided another approach to the study of CNT toxicity where conditions can be more easily manipulated. Reports using primary or immortal cell lines of the CNS glia and neurons have yielded mixed results. For example, the BV2 microglia cell line was unaffected by MWCNTs (Kateb et al., 2007), while the DNA content of primary microglia in mixed neuro-glia or glia-enriched cultures were reduced by exposure to SWCNTs (Belyanskaya et al., 2009).

The PC1 2 pheochromocytoma line widely used as a neuronal cell model (Greene and Tischler, 1976) shows various signs of stress and/or apoptosis when exposed to relatively low concentrations of cadmium telluride quantum dots (Lovric et al., 2005) or Mn, Ag or Cu nanoparticles (Hussain et al., 2006; Rossi et al., 2006). However, this same cell line showed no signs of toxicity after exposure to MWCNTs (Xu et al., 2009). Furthermore, in primary cortical neurons, MWCNTs protected against toxicity induced by the nonionic detergent PF1 27 (Bardi et al., 2009).

We report here the extent and nature of MWCNT toxicity using the NS-1 cell line, a rapidly growing, highly adherent line derived from PC1 2 cells. Specifically, we examined MWCNT effects on cell metabolism, plasma membrane translocation and permeability, DNA integrity, caspase $3 / 7$ activity and mitochondrial membrane depolarization. We chose to study MWCNTs rather than SWCNTs for several reasons. First, MWCNTs are currently more widely available at significantly lower cost than SWCNTs. Second, SWCNT synthesis is favored at a higher metal to carbon ratio (Lam et al., 2006), a process that increases the level of metal impurities and the likelihood of toxicity. Third, SWCNTs have proven more toxic in in vitro studies (Lovric et al., 2005; Magrez et al., 2006). Finally, humans and other organisms are exposed to MWCNTs generated by fuel combustion (Lam et al., 2006).

\section{Materials and Methods}

\section{Carbon Nanotubes}

MWCNTs were either purchased from Nanomaterials Store (Fremont, CA) or received as a gift from Jie Liu (Duke University, Durham, NC). Both materials, designated CNT-CA and CNT-D, were synthesized by chemical vapor deposition with $\mathrm{Fe}$ or $\mathrm{Co}$. CNT-CA was $>99 \%$ pure (diameter $=10-20 \mathrm{~nm}$, length $=10-30$ microns). CNT-D contained $<0.1 \% \mathrm{Fe}$ as judged by inductively coupled plasma (ICP) spectroscopy. Dynamic light scattering estimated particle hydrodiameter at 85-115 nm $(p<0.5)$.

MWCNTs were solubilized by sonication and vortexing in treatment media (RPMI 1640 containing $100 \mu \mathrm{g} / \mathrm{mL}$ penicillin/streptomycin). The remaining insoluble particles were removed by filtration through a 0.45 micron polyethersulfone (PES) filter (Pall Corporation, Port Washington, NY). The concentration of soluble MWCNTs was 190 ppm (CNT-CA) and 295 ppm (CNT-D) as determined by total organic carbon (TOC) analyzer (Shimadzu, Japan).

\section{Tissue Culture}

NS-1 cells purchased from Cellomics Inc. (Pittsburgh, PA) were maintained in culture media consisting of RPMI 1640, 10\% fetal bovine serum (FBS), $2 \mathrm{mM}$ glutamine and $100 \mu \mathrm{g} / \mathrm{mL}$ penicillin/ streptomycin (pen/strep) at $37^{\circ} \mathrm{C}$ in $5 \% \mathrm{CO}_{2}, 90 \%$ humidity and plated at $1 \times 10^{4}$ cells per well in 96 -well or $5 \times 10^{5}$ cells per well in 6 well microtiter plates for assays.

\section{Viability Assay (Redox System)}

Cells were plated overnight at in 96 well plates and then treated with MWCNTs. At indicated times resazurin (Sigma, St. Louis, MO) in Dulbecco's phosphate buffered saline without calcium and magnesium (PBS) was added to the wells (final concentration $0.1 \mathrm{mg} / \mathrm{mL}$ ) and incubated at $37^{\circ} \mathrm{C}$ for 2 hours. The reduction of resazurin to resorufin was measured fluorometrically $\left(\lambda_{\text {exc }} 560 \mathrm{~nm} / \lambda_{\text {em }} 590 \mathrm{~nm}\right)$ using a PheraStar Plus plate reader (BMG Labtech, Cary, NC). Data were processed using MARS Data Analysis (BMG Labtech) software.

\section{Viability Assay (In Situ)}

Following CNT or control treatment for $48 \mathrm{~h}$, cells were double stained with a mixture of Hoechst 33342 (Invitrogen, Carlsbad, CA) and propidium iodide (PI) (Sigma, St Louis, MO). The dyes were added to a final concentration of $2 \mu \mathrm{g} / \mathrm{mL}$ and $5 \mu \mathrm{g} /$ $\mathrm{mL}$, respectively. Cells were incubated for $30 \mathrm{~min}$ at room temperature (RT) and imaged on a BD Pathway Finder ${ }^{T M} 855$ High $^{2}$ Content Screening (HCS) imaging platform using a 20X LWD objective. A $3 \times 3$ montage image was collected for each well. Each treatment condition was performed in quadruplicate (average of 1000 total nuclei per well). The resulting images were segmented for nuclei using BD AttoVision ${ }^{T M}$ Software version 6.1.

\section{Apoptosis/Necrosis Assay (Annexin V/PI Double Stain)}

Cells were plated overnight, rinsed with serum free medium (SFM) and treated with CNTs or $10 \mu \mathrm{M}$ etoposide (Calbiochem, Darmstadt, Germany) at $37^{\circ} \mathrm{C}$ for the indicated times. After rinsing with SFM, cells were harvested and washed in cold PBS and resuspended to a density of $1 \times 10^{6}$ cells $/ \mathrm{mL}$ in annexin-binding buffer $10 \mathrm{mM}$ HEPES, $140 \mathrm{mM} \mathrm{NaCl}$ and $2.5 \mathrm{mM} \mathrm{CaCl}, \mathrm{pH}$ 7.4). A $5 \mu \mathrm{L}$ aliquot of annexin V-FITC and PI $(5 \mu \mathrm{g} / \mathrm{mL}$ final concentration) were added to $100 \mu \mathrm{L}$ samples. Samples were incubated at RT for $15 \mathrm{~min}$ and diluted with $400 \mu \mathrm{L}$ annexin binding buffer, gently mixed and transferred to ice. Samples were analyzed on a BD FACSAria ${ }^{T M}$ cytometer (Becton Dickinson, Mountain View, CA) using FACSDiva ${ }^{T M}$ software version 6.1 using $\lambda_{\text {exc }} 488 \mathrm{~nm} / \lambda_{\mathrm{em}} 518 \mathrm{~nm}$.

\section{Mitochondrial Membrane Potential (JC-1)}

NS- 1 cells were plated overnight at $37^{\circ} \mathrm{C}$, washed twice with PBS and incubated with CNT preparations at $37^{\circ} \mathrm{C}$ for $48 \mathrm{~h}$ prior to analysis. Cells were harvested, washed and loaded for $1 \mathrm{~h}$ at $37^{\circ} \mathrm{C}$ with $6 \mu \mathrm{g} / \mathrm{mL} \mathrm{JC}-1$ (Invitrogen, Carlsbad, CA) and data 
were collected on a BD FACSAria ${ }^{T M}$ cytometer using FACSDiva ${ }^{T M}$ software version 6 . Valinomycin treated cells (1 $\mu \mathrm{M})$ were used to produce gates separating cells with polarized versus depolarized (valinomycin-treated) mitochondria. To enhance spectral separation, the red "J-aggregate" fluorescence generated by polarized mitochondria was monitored at $610 \mathrm{~nm}$ and the green JC- 1 monomer was detected at $530 \mathrm{~nm}$. Fluorescence compensation was applied to enhance resolution of cells with decreased mitochondrial membrane potential.

\section{Cell Cycle Analysis (PI)}

Adherent cells were harvested, washed in PBS and suspended at $1 \times 10^{6}$ to $1 \times 10^{7}$ cells in $500 \mu \mathrm{L}$ PBS to a uniform single cell suspension. Cells were transferred to ice and fixed in $4.5 \mathrm{~mL}$ cold $70 \%$ ethanol for at least two hours. Cells were rinsed briefly in PBS and suspended in $1 \mathrm{~mL}$ PI staining solution containing $0.1 \%$ v/v Triton X-100 (Sigma, St. Louis, MO), 0.2 mg/mL DNase-free RNase A (Sigma) and $20 \mu \mathrm{g} / \mathrm{mL}$ PI for $30 \mathrm{~min}$ at RT. Samples were analyzed on a BD FACSAria ${ }^{T M}$ cytometer using FACSDiva $^{T M}$ software version 6.1. The hypodiploid population of cells was identified as apoptotic.

\section{Apoptosis Assay (Caspase 3/7)}

Caspase 3/7-like activity was assayed using the Apo-ONE homogeneous caspase- $3 / 7$ assay kit (Promega, Madison, WI) with $10 \mu \mathrm{M}$ etoposide as a positive control (Hishita et al., 2001). Fluorescence $\left(\lambda_{\text {exc }} 485 \mathrm{~nm} / \lambda_{\text {em }} 535 \mathrm{~nm}\right.$ ) was measured using a $\mathrm{Ph}$ eraStar Plus microplate reader.

\section{Statistical Analysis}

Data with error bars are presented as means \pm standard deviation (SD) of at least three separate experiments done in triplicates. ANOVA and Turkey's multiple comparison tests were performed in GraphPad PRISM 5.0 (GraphPad Software Inc., San Diego, CA). Values of $p$ less than $(<) 0.05$ were considered statistically significant.
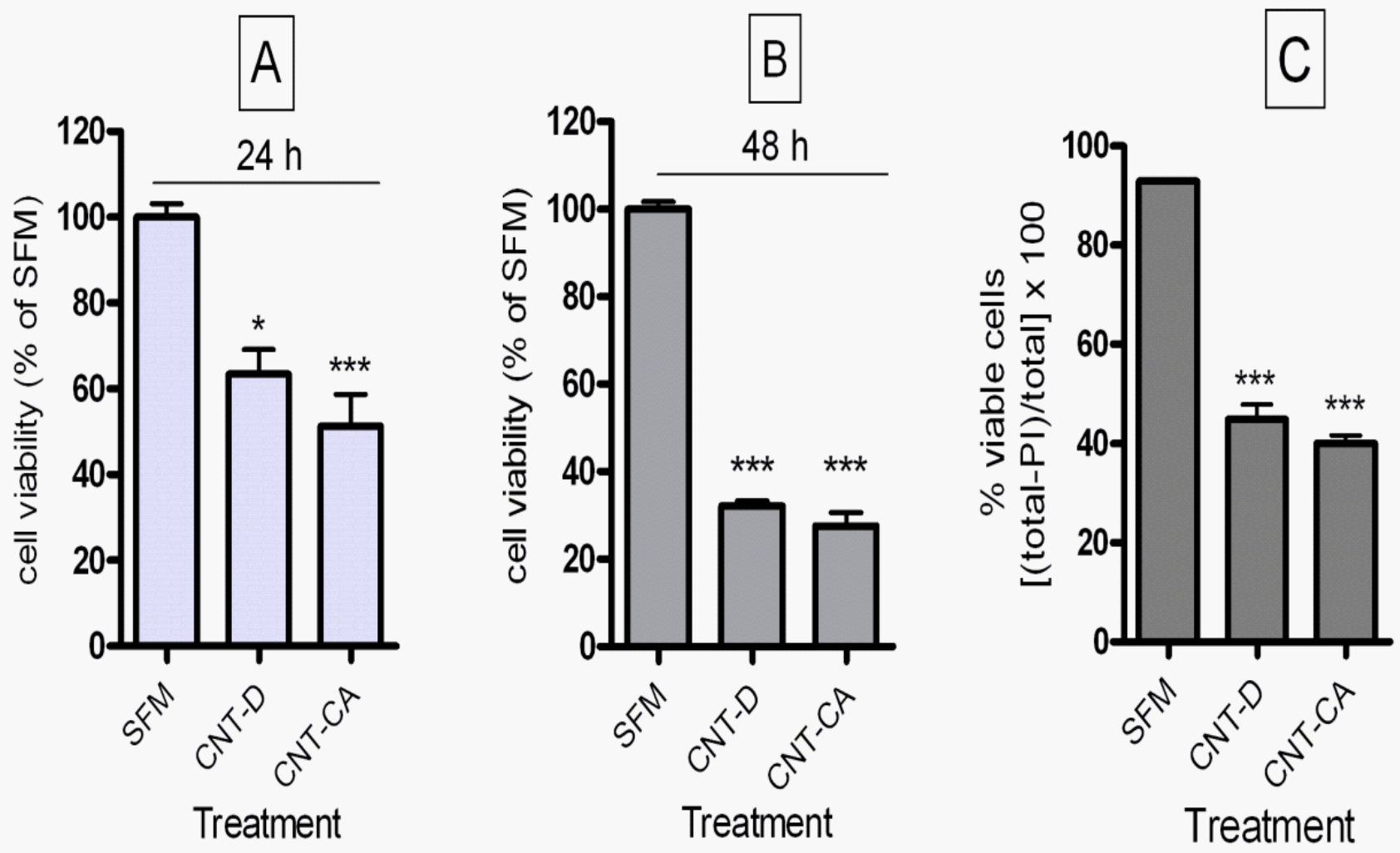

Fig. 1. Viability of NS1 cells exposed to CNTs. NS1 cells were exposed to SFM or carbon nanotubes for $24 \mathrm{~h}$ (A) or $48 \mathrm{~h}$ (B) and assayed for metabolic activity. Alternately, cells were double stained with Hoechst 33342 and PI as in situ measure of viability (C). Percentage of viable cells was calculated as the ratio of (Hoechst nuclei - PI nuclei)/Hoechst nuclei. Results represent means \pm SD of three experiments in triplicates. *,*** indicates $p<0.01$, and $p<0.001$ compared to SFM. 


\section{Results}

\section{MWCNTs reduce NSI Neuronal Cell Viability}

In order to investigate the neurotoxicity of MWCNTs, we selected NS- 1 cells, a subclone of the PC12, a pheochromocytoma line used as in vitro neuronal model (Greene and Tischler, 1976). NS- 1 metabolic activity was assayed using resazurin conversion to resorufin as a biochemical measure of cell viability (Magnani and Bettini, 2000). MWCNTs from two sources inhibited NS-1 viability as compared with cells grown in either culture medium or SFM (Fig 1).

Figure 1A shows treatment of cells with MWCNTs resulted in a decrease of more than $40 \%$ in resazurin conversion capability after $24 \mathrm{~h}$. The toxic effects of CNTs were even more pronounced by $48 \mathrm{~h}$ when the extent of metabolic inhibition was approximately $70 \%$ (Fig. 1B). Only the highest concentrations of solubilized MWCNTs (190 ppm for CNT-CA and 295 ppm for CNT-D) showed toxic effects; when diluted, the MWCNTs had no effect on cells (data not shown).

Cell viability was also measured using an in situ assay of plasma membrane integrity (Fig. 1C). Automated measurements compared total cell nuclei (stained with Hoechst 33342) and nuclei from cells with compromised plasma membranes (stained with PI). Less than half the cells treated with MWCNTs had intact plasma membranes by $48 \mathrm{~h}$. In both viability assays, CNT-CA was slightly but consistently more toxic than CNT-D. In order to test the limits of MWCNT toxicity, we conducted the majority of our subsequent studies with CNT-CA.

\section{MWCNTs Promote Gradual Phosphatidylserine Translocation}

There are two well described paths to cell death: apoptosis, which is a natural and controlled process, and necrosis, which is unordered and more destructive. Since MWCNTs reduced NS- 1 cell viability, we tested whether MWCNTs stimulated apoptosis, necrosis or both using a double-stain flow cytometric assay. One of the earliest events in apoptosis is the translocation of phosphatidylserine (PS) phospholipids from the cytoplasmic face to the extracellular face of the plasma membrane. The protein annexin $V(A n x V)$ has a high affinity for PS in the presence of calcium and, when conjugated with a fluorescent probe such as FITC, can be used to assay for newly exposed PS. When simultaneously stained with $\mathrm{Pl}$, a dye specific for staining the nucleus in cells with compromised membrane, test cells can be identified as belonging to one of four categories: normal (AnxV and PI negative), early apoptotic (AnxV positive, PI negative), late apoptotic (AnxV and PI positive) and necrotic (AnxV negative, PI positive).

NS- 1 cells plated in cell growth medium were allowed to attach and recover following overnight incubations in a humidified $37^{\circ} \mathrm{C}$ incubator. The growth medium was replaced with the CNTCA solution after a brief PBS rinse. The cells were harvested at $6,10,24,48$ or $72 \mathrm{~h}$, and $1 \times 10^{6}$ cells double stained with AnxV-FITC and PI, and analyzed by flow cytometry to determine the condition of the cells. A topoisomerase II inhibitor, etoposide $(10 \mu \mathrm{M})$, was used as a positive control for loss of plasma membrane asymmetry. Fig $2 \mathrm{~A}$ shows the scatter plots cytograms
$2 \mathrm{~A}$

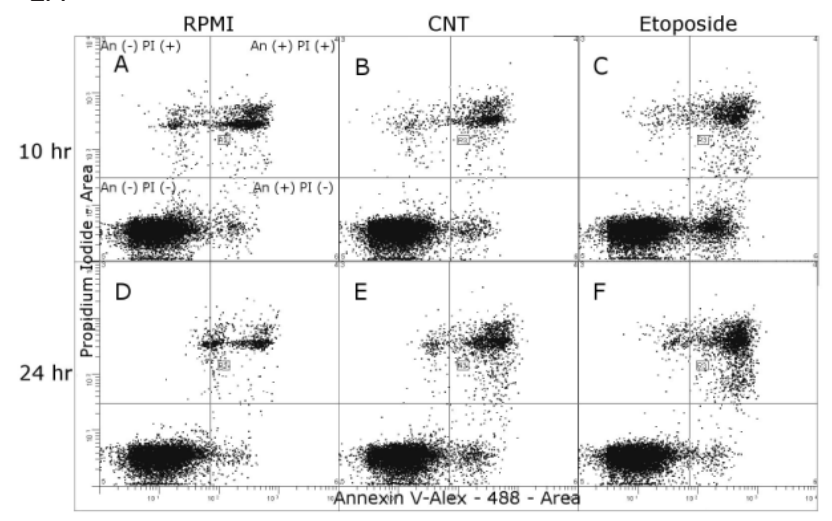

$2 B$
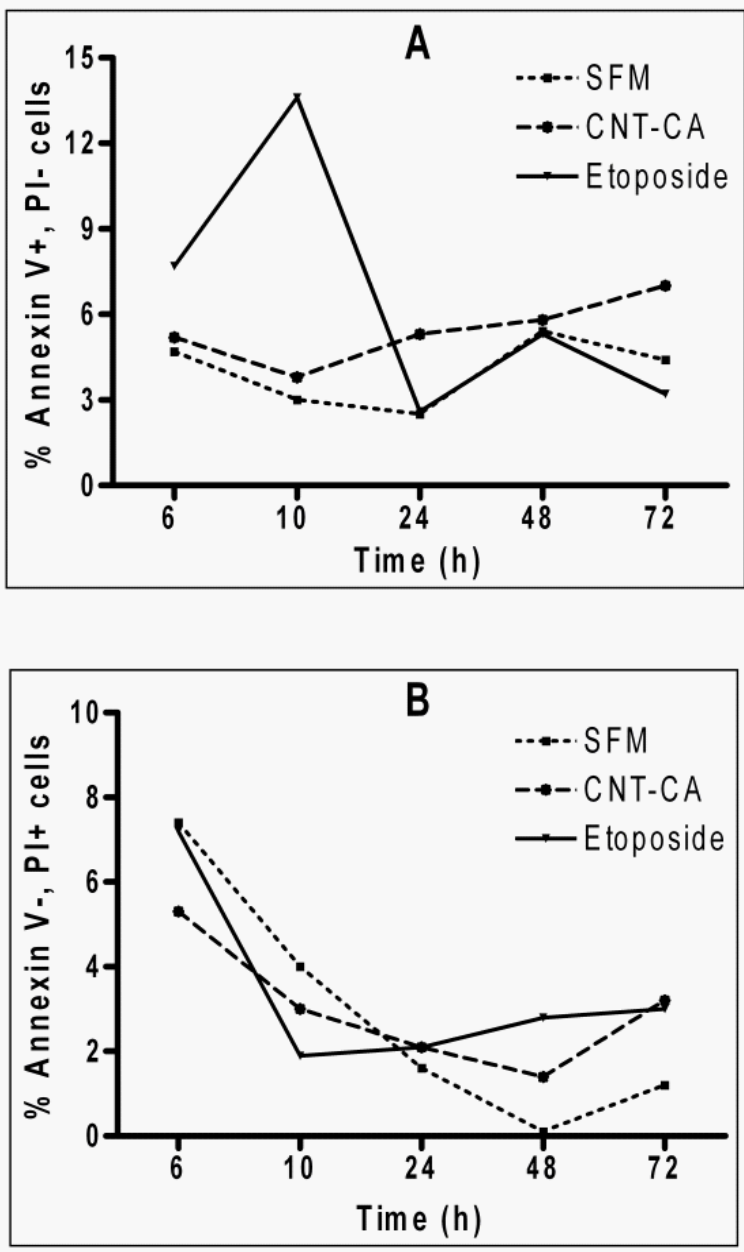

Fig. 2. Analysis of the effects of CNTs on cell state by flow cytometry. NSI cells were treated with SFM, CNT-CA or etoposide, double-stained with annexin V-FITC and PI and analyzed by flow cytometry. Panel 2A represents the scatter plots at $10 \mathrm{~h}(\mathrm{~A}-\mathrm{C})$ and $24 \mathrm{~h}(\mathrm{D}-\mathrm{F})$ exposures to $\operatorname{SFM}(A, D), C N T(B, E)$ and etoposide $(C, F)$. The line graphs in panel $2 B$ represent the time course of generation of early apoptotic $(A)$, or necrotic (B) cell populations in cells treated with SFM (O), CNT-CA (*), or etoposide ( $\mathbf{\square})$. 
generated at 10 and $24 \mathrm{~h}$ after treatment with SFM, CNT or etoposide. Each result is shown as a panel partitioned into four sections with cells represented as dots distributed in the four staining categories, $\mathrm{An}(-) \mathrm{PI}(+), \mathrm{An}(+) \mathrm{PI}(+), \mathrm{An}(+) \mathrm{PI}(-)$, and $\mathrm{An}(-) \mathrm{PI}(-)$.

In comparing the data from treated cells harvested at $10 \mathrm{~h}$
(Fig. 2A, panels A-C), only etoposide produced a notable increase in the population of early apoptotic cells, An(+) $\mathrm{PI}(-)$, when compared with SFM and CNT treated cells, as shown in the lower right quadrant in panels A-C. By $24 \mathrm{~h}$ (Fig. 2A, panels $D-F), C N T$ treated cells showed an increase in the population of AnxV reactive (PS translocated) cells, both with and without

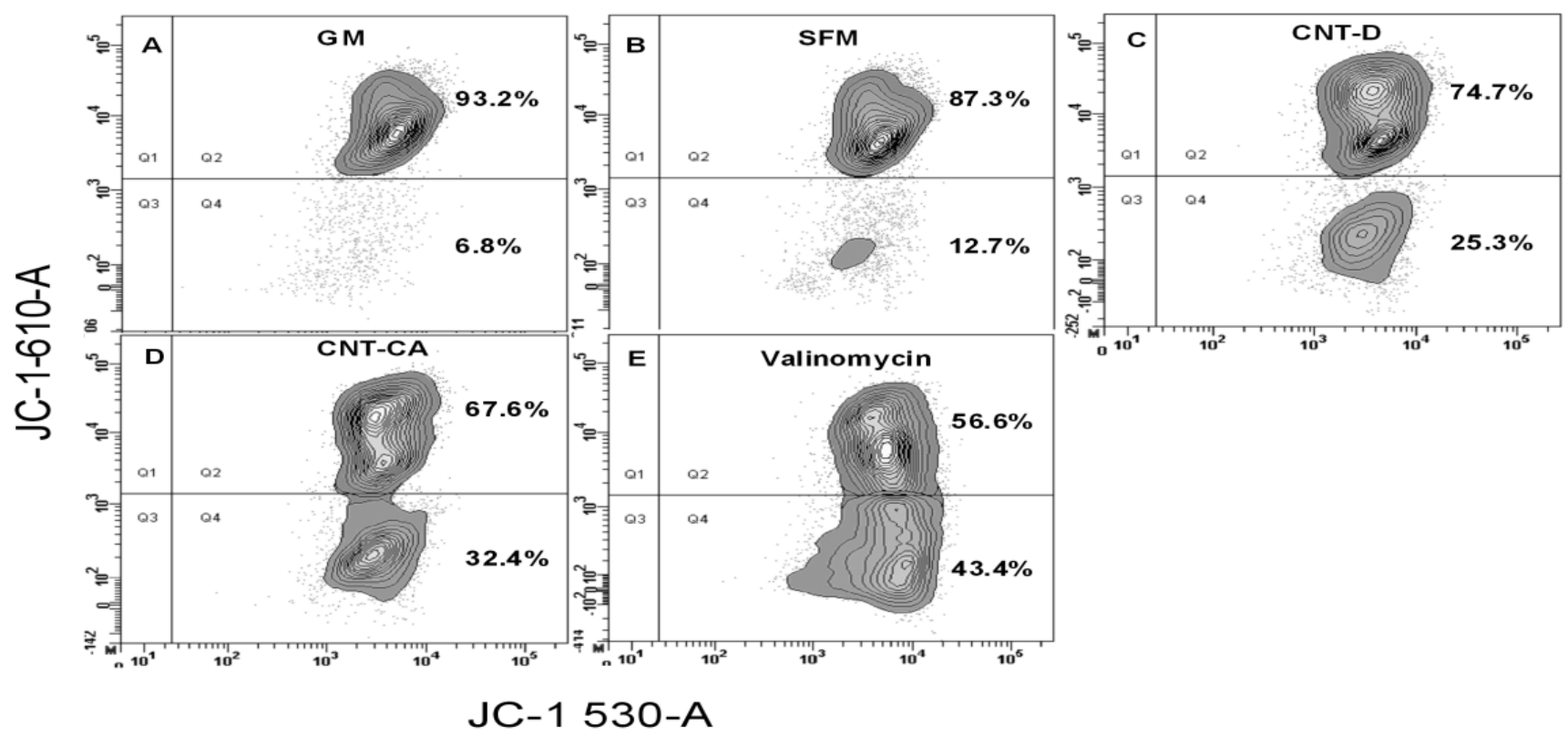

Fig. 3. CNTs depolarize mitochondrial membrane. NS1 cells were exposed to cell GM (A), SFM (B), CNT-D (C), or CNT-CA (D) for 48 h or valinomycin for $2 \mathrm{~h}(\mathrm{E})$, harvested and loaded with JC-1 dye for $1 \mathrm{~h}$. Cells were analyzed by flow cytometry using gates to separate and quantify fluorescence of green monomer and red aggregates in cell populations.

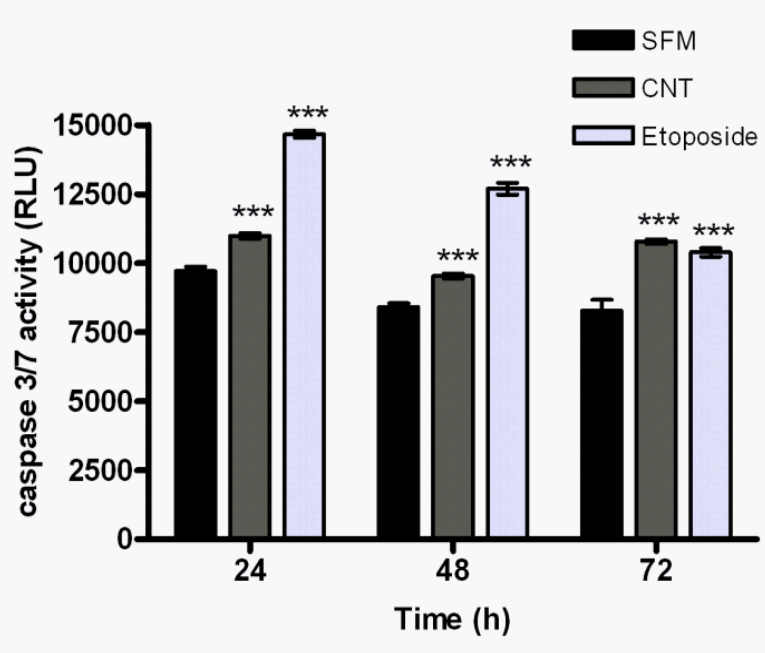

Fig. 4. CNTs induce caspase $3 / 7$ activity. NS1 cells were exposed to SFM, CNT-CA or etoposide for 24,48 or $72 \mathrm{~h}$ and assayed for caspase $3 / 7$ activity. Results represent the means + S.D. of four independent experiments tested in triplicates. ${ }^{* * *}$ indicates $p<0.001$ compared with SFM.
Table 1. Percentage of Hypodiploid (Apoptotic) Cells Produced by CNT and Control Treatments.

\begin{tabular}{lcc}
\hline Treatment & $\mathbf{4 8} \mathbf{h}$ & $\mathbf{7 2} \mathbf{h}$ \\
\hline GM & 6.27 & 6.29 \\
SFM & 16.39 & 22.18 \\
CNT-CA & 27.64 & 46.04 \\
Etoposide & 46.68 & 38.48 \\
\hline
\end{tabular}

increased membrane permeability (Fig. 2A, panel E, upper and lower right quadrants), relative to the control (SFM) cells (panel D) and on par with etoposide treated cells (panel F). However, data collected over the full time course of the experiment indicated a more complex pattern.

Cell death can occur by two distinct methods, apoptosis and necrosis. Although AnxV-FITC and PI double staining provides an efficient means to identify cells which have undergone apoptosis, the identification of cells that died through necrosis by this method is less well defined for single observations. However, when samples are analyzed over a period of time it is possible to identify population of cells which have undergone necrosis. 
Therefore to clarify whether CNT induces necrosis in addition to apoptosis, we analyzed the effects of the treatments by plotting the data obtained at $6,10,24,48$ and $72 \mathrm{~h}$ for the apoptotic $\mathrm{An}(+) \mathrm{PI}(-)$ and potentially necrotic $\mathrm{An}(-) \mathrm{PI}(+)$ cells. Figure $2 \mathrm{~B}$ displays the time course of generation of these two abnormal cell states following SFM, CNT, and etoposide treatment. We note first that etoposide-induced PS translocation preceding loss of membrane integrity (early apoptosis) is maximal at $10 \mathrm{~h}$ (Fig. 2B-A). In contrast, neither SFM nor CNT treated cells display any sign of increased AnxV reactivity at $10 \mathrm{~h}$. Second, there was little difference in the percentage of necrotic cells among the treatment groups for the first $24 \mathrm{~h}$ (Fig. 2B-B), and since the percentage of necrotic cells is relatively low and generally decreased with time, the data suggest that neither etoposide nor MWCNTs induce neuronal cell death via necrosis.

\section{MWCNTs Induce Mitochondrial Membrane Depolarization}

Since MWCNTs appear to induce neuronal apoptosis, albeit at a slow $(48-72 \mathrm{~h})$ rate, we explored their effects on three key cellular processes associated with apoptosis: mitochondrial membrane depolarization, DNA fragmentation, and induction of caspase activity. We examined CNT effects on mitochondrial membrane potential as a measure of intrinsic apoptosis using JC-1, a dye which is selectively permeable to mitochondria and emits an altered wavelength as it aggregates in the interior of normally polarized mitochondria. NS-1 cells seeded in $10 \mathrm{~cm}^{2}$ culture plates with complete growth medium (GM) were incubated overnight at $37^{\circ} \mathrm{C}$ in a humidified incubator. The cells were washed with PBS and treated with treated with $10 \mathrm{~mL}$ of $\mathrm{MW}$ CNTs, SFM or GM for $48 \mathrm{~h}$. Cells treated for $2 \mathrm{~h}$ with $1 \mu \mathrm{M}$ valinomycin, an antibiotic that negatively modulates mitochondrial oxidative phosphorylation through the formation of potassium ion permeable pores, served as depolarized control (Fig 3).

FACS analysis of the treated cells showed that both CNT-D and CNT-CA decreased the number of polarized cells at $74.7 \%$ and $67.6 \%$ respectively (Fig 3, panels C, D) compared with $87.3 \%$ for SFM control (Fig 3, panel B). CNT-CA was slightly more destructive to the mitochondrial membrane at $32.4 \%$ (Fig. 3 , panel D) than CNT-D at $25.3 \%$ (Fig. 3, panel C), relative to SFM at $12.7 \%$. Over $93 \%$ of the population of cells grown in GM exhibited intact mitochondrial membrane while cells treated with the ionophore valinomycin resulted in greater than $43 \%$ mitochondrial depolarization.

\section{MWCNTs Produce An Increased Hypodiploid Population of Cells}

Using PI DNA stain and flow cytometry, we measured the formation of cells with a lower PI signal than that of normal diploid cells (hypodiploid cells). The percentage of hypodiploid cells measured at $48 \mathrm{~h}$ and $72 \mathrm{~h}$ following exposure of cells to CNT-CA and etoposide with GM and SFM as controls are shown in Table 1. CNT exposure for $48 \mathrm{~h}$ increased the percentage of apoptotic cells by four-fold compared with GM. By $72 \mathrm{~h}$ the difference in cells treated with CNT-CA compared to those maintained in GM was more than seven-fold. Cells in SFM also began to show signs of apoptosis at the two time points evalu- ated. However, at $72 \mathrm{~h}$ CNT-induced apoptosis was more than twice that induced by serum withdrawal. Also, CNT produced a greater percentage of hypodiploid cells by $72 \mathrm{~h}$ compared to etoposide under serum-free conditions.

\section{MWCNTs Induce Delayed Caspase 3/7 Activity}

The two major pathways known to induce apoptosis, the receptor-mediated extrinsic pathway and the mitochondrial-activated intrinsic pathway, both involve the activation of the executioner caspase 3 protein. Caspase 7, another apoptotic executioner protein, shares substrate specificity with caspase 3 and its activity is also measured by this assay. Therefore, we looked for signs of caspase $3 / 7$ activity in NS- 1 cells treated with CNTs compared to SFM and etoposide (Fig 4). CNT-CA induced marginal but significant caspase $3 / 7$ activity over SFM but less that etoposide after $24 \mathrm{~h}$ of incubation. By $48 \mathrm{~h}$ there was a slight overall decrease in the levels of caspase $3 / 7$ compared to those observed at $24 \mathrm{~h}$. However, by $72 \mathrm{~h}$ CNT-treated cells continued to produce a sustained level of activated caspase $3 / 7$ while no change was observed in SFM cultures cells. Compared to the $24 \mathrm{~h}$ time point, the pronounced decrease in caspase $3 / 7$ activity in etoposide treated cells is likely due to compound toxicity resulting in low numbers of viable cells after $72 \mathrm{~h}$ under etoposide tension. These results imply that caspase $3 / 7$ is activated in NS- 1 cells by exposure to CNT and participates in cell damage, apoptosis and ultimately, death of neuronal cells.

\section{Discussion}

The wide use of nanoscale materials in products as diverse as foods, cosmetics, drugs and medical devices raise unique safety concerns for industry and regulators. Reports on the toxicity profile of these materials are limited. However, it is becoming evident that their effects on cells systems are very dynamic and are dependent on cell types and the physicochemical characteristics of the material. In this study we report the effects of MWCNTs on NS-1, a neuronal cell model derived from PC12. Our findings show that only the highest concentrations of solubilized MWCNTs (190 ppm CNT-CA and 295 ppm CNT-D) compromised the viability of NS-1 cells. In comparison with the toxic effects of non-carbon nanoparticles on $\mathrm{PC} 12$ cells, MWCNTs are relatively well-tolerated. Much lower concentrations ( $5 \mathrm{ppm} / 5 \mu \mathrm{g} / \mathrm{mL}$ ) of MWCNTs had no effect on PC1 2 viability (Xu et al., 2009) even though cadmium telluride quantum dots (Lovric et al., 2005), and $\mathrm{Mn}, \mathrm{Ag}$ or $\mathrm{Cu}$ nanoparticles are cytotoxic at just 10 ppm (Hussain et al., 2006; Rossi et al., 2006). Like PC12, the human neuroblastoma line SH-SY5Y also tolerated MWCNTs at low concentrations, i.e. 5-10 ppm [19]. Nevertheless, we found that at sufficiently high concentrations, MWCNTs reduced NS 1 viability as measured metabolically by cellular enzyme conversion of resazurin to resorufin and structurally using the comparison of total nuclear staining by Hoechst 33342 with nuclear staining of cells with damaged plasma membranes by $\mathrm{PI}$.

CNT-induced cell death was apoptotic and not necrotic. NS-1 cells were treated with CNTs compared to serum-free or etoposide controls for various lengths of time and double-stained with 
PS reactive AnxV-FITC and PI. While necrotic cell populations remained at or below levels measured at the initial $6 \mathrm{~h}$ time point, early and late apoptotic cell populations increased with length of CNT exposure. Etoposide optimally induced early stages of apoptosis by $10 \mathrm{~h}$; this timeframe is consistent with that reported by Denecker et al. (2000). In contrast, induction of apoptosis by CNTs was not easily observed until $24 \mathrm{~h}$ of exposure.

Although CNT-induced apoptosis occurred more slowly, by 72 hours CNT toxicity was more extensive than that of etoposide. Similar timeframes for CNT and etoposide toxicity were also seen in assays measuring the loss of DNA integrity and the modest increase in caspase $3 / 7$ activity. Our observation that sensitivity to etoposide decreases by $72 \mathrm{~h}$ is likely a function of its mechanism of action as a DNA topoisomerase II inhibitor; only the subset of cells in S and G2 phases are affected and in the absence of serum, cells enter into quiescent GO and are unsusceptible to etoposide. Thus, our experimental design does not allow for comparison of CNTs and etoposide at time points beyond 24-48 h.

As to the more important question of overall CNT toxicity in the brain, recent in vitro studies of microglia, astrocytes and complex primary cultures have suggested neurons may be more resilient than their accessory cells. Although we are unaware of any data comparing CNT effects on neurons and accessory cells, Long and coworkers (Long et al., 2007) compared the effects of $\mathrm{TiO} 2$ nanoparticles on neurons and microglia. Immortalized rat $\mathrm{N} 27$ mesencephalic neurons tolerated up to 120 ppm TiO2 nanoparticles for three days without a significant reduction in Hoechst live cell staining. In contrast, mouse BV2 microglia was found to be highly sensitive to $\mathrm{TiO} 2$ nanoparticles at only 2.5 ppm. In addition, complex primary cultures of rat striatum (containing glia and neurons) incurred a $14 \%$ loss of neural cells after $6 \mathrm{~h}$ in 5 ppm TiO2 nanoparticles. Similarly, Belyanskaya et al. [8] tested the effects of single walled (SW) CNTs at 30 ppm on primary cultures of embryonic chicken spinal cord and found an overall decrease in DNA content after 6 days. Using cell type specific antibodies they determined that the loss of DNA was due to glia, not neural, cell death.

Since complex primary cultures contain several cell types, it is not clear yet whether microglia or other neuroglia type cells are responsible for neural cell damage. For example, astrocytes may also play a role in neuronal toxicity. When primary rat neurons were co-cultured with purified primary astrocytes or microglia, neurons were protected from agents that induce reactive oxygen and nitrogen species (Tanaka et al., 1999). On the other hand, toxic agents such as the Alzheimer's $A \beta$ peptide stimulate primary rat astrocytes to produce ROS and pro-inflammatory cytokines (Johnstone et al., 1999). Along these lines, Sayes and co-workers have shown that neuronal human astrocytes (NHA) are damaged by as little as 0.24 ppm nano-C60 fullerene, another carbon nanoparticle (Sayes et al., 2005). If astrocyte distress promotes neuronal toxicity as does microglia distress, CNTs may be indirectly toxic to neurons because of CNT damage to supporting glia, not because of their effect on the neurons themselves.

\section{Conclusion}

The widespread application of nanotechnology and the potential impact of MWCNTs on the environment and human health, particularly in occupational exposure settings, have led us to initiate an investigation of the effect of this material in a cultured neuron model. We find that MWCNT toxicity occurs at a slower rate than etoposide and requires relatively long exposure to induce cell death. Cell death occurs via apoptosis with serine translocation by $24 \mathrm{~h}$, mitochondrial membrane depolarization by $48 \mathrm{~h}$, DNA fragmentation by $48-72 \mathrm{~h}$ and modest caspase 3 activation by $72 \mathrm{~h}$. Further research is ongoing to determine the molecular mechanism of delayed MWCNT toxicity in cultured neurons.

\section{Acknowledgments}

This work was supported in part by a grant from the GoldenLEAF Foundation and funds from the State of North Carolina. The authors wish to thank Dr. Susan Peacock, J.D., Ph.D. for assistance with the review of this manuscript. The authors appreciate Dr. Appala Raju badireddy and Dr. Mark Wiesner, Center for Environmental Implications of nanotechnology, Duke University, Durham, for their technical support in carbon nanotube characterization.

\section{References}

Bardi G, P Tognini, G Ciofani, V Raffa, M Costa, and T Pizzorusso (2009) Pluronic-coated carbon nanotubes do not induce degeneration of cortical neurons in vivo and in vitro, Nanomedicine 5: 96-104.

Baughman RH, AA Zakhidov, and WA de Heer (2002) Carbon nanotubes--the route toward applications. Science 297: 787-792.

Belyanskaya L, S Weigel, C Hirsch, U Tobler, HF Krug, and P Wick (2009) Effects of carbon nanotubes on primary neurons and glial cells, Neurotoxicology 30: 702-711.

Denecker G, H Dooms, G Van Loo, D Vercammen, J Grooten, W Fiers, W Declercq, and P Vandenabeele (2000) Phosphatidyl serine exposure during apoptosis precedes release of cytochrome $c$ and decrease in mitochondrial transmembrane potential. FEBS Lett 465: 47-52.

El-Ansary A and S Al-Daihan (2009) On the toxicity of therapeutically used nanoparticles: an overview. J Toxicol 754-810.

Greene LA, and AS Tischler (1976) Establishment of a noradrenergic clonal line of rat adrenal pheochromocytoma cells which respond to nerve growth factor, Proc Natl Acad Sci U S A 73: 2424-2428.

Hishita T, S Tada-Oikawa, K Tohyama, Y Miura, T Nishihara, Y Tohyama, Y. Yoshida, T Uchiyama, and S Kawanishi (2001) Caspase-3 activation by lysosomal enzymes in cytochrome c-independent apoptosis in myelodysplastic syndrome-derived cell line P39. Cancer Res 61: 2878-2884.

Hussain SM, AK Javorina, AM Schrand, HM Duhart, SF Ali, and JJ Schlager (2006) The interaction of manganese nanoparticles with PC-1 2 cells induces dopamine depletion. Toxicol Sci 92: 456-463.

Johnstone M, AJ Gearing, and KM Miller (1999) A central role for astrocytes in the inflammatory response to beta-amyloid; chemokines, cytokines and reactive oxygen species are produced, J Neuroimmunol 93: 182-193.

Kahru A, and HC Dubourguier (2010) From ecotoxicology to nanoecotoxicology. Toxicology 269: 105-119. 
Kateb B, M Van Handel, L Zhang, MJ Bronikowski, H Manohara, and B Badie (2007) Internalization of MWCNTs by microglia: possible application in immunotherapy of brain tumors, Neuroimage 37 Suppl 1: S9-17.

Lam CW, JT James, R McCluskey, S Arepalli, and RL Hunter (2006) A review of carbon nanotube toxicity and assessment of potential occupational and environmental health risks. Crit Rev Toxicol 36: 189-217.

Long TC, J Tajuba, P Sama, N Saleh, C Swartz, J Parker, S Hester, GV Lowry, and B Veronesi (2007) Nanosize titanium dioxide stimulates reactive oxygen species in brain microglia and damages neurons in vitro. Environ Health Perspect 115: 1631-1637.

Lovric J, HS Bazzi, Y Cuie, GR Fortin, FM Winnik, and D Maysinger (2005) Differences in subcellular distribution and toxicity of green and red emitting CdTe quantum dots, J Mol Med 83: 377-385.

Madl AK and KE Pinkerton (2009) Health effects of inhaled engineered and incidental nanoparticles, Crit Rev Toxicol 39: 629-658.

Magnani E and E Bettini (2000) Resazurin detection of energy metabolism changes in serum-starved $\mathrm{PC} 12$ cells and of neuroprotective agent effect. Brain Res Brain Res Protoc 5: 266-272.

Magrez A, S Kasas, V Salicio, N Pasquier, JW Seo, M Celio, S Catsicas, B Schwaller, and L Forro (2006) Cellular toxicity of carbon-based nanomaterials. Nano Lett 6: 1121-1125.

Malarkey EB and V Parpura (2007) Applications of carbon nanotubes in neurobiology. Neurodegener Dis 4: 292-299.

Rossi L, M Arciello, C Capo, and G Rotilio (2006) Copper imbalance and oxidative stress in neurodegeneration. Ital J Biochem 55: 212 221.

Saito N, Y Usui, K Aoki, N Narita, M Shimizu, K Hara, N Ogiwara, K Nakamura, N Ishigaki, H Kato, S Taruta, and M Endo (2009) Carbon nanotubes: biomaterial applications. Chem Soc Rev 38: 1897-1903.

Sayes CM, AM Gobin, KD Ausman, J Mendez, JL West, and VL Colvin (2005) Nano-C60 cytotoxicity is due to lipid peroxidation. Biomaterials 26: 7587-7595.

Tanaka J, K Toku, B Zhang, K Ishihara, M Sakanaka, and N Maeda (1999) Astrocytes prevent neuronal death induced by reactive oxygen and nitrogen species. Glia 28: 85-96.

Vittorio O, V Raffa, and A Cuschieri (2009) Influence of purity and surface oxidation on cytotoxicity of multiwalled carbon nanotubes with human neuroblastoma cells. Nanomedicine 5: 424-431.

Xu H, J Bai, J Meng, W Hao, and JM Cao (2009) Multi-walled carbon nanotubes suppress potassium channel activities in $\mathrm{PC} 12$ cells. Nanotechnology 20: 285102. 